Curr Opin Clin Nutr Metab Care. 2010 July ; 13(4): 471-477. doi:10.1097/MCO.0b013e32833a558d.

\title{
Genetics of Type 2 Diabetes
}

\author{
Dr. Galina Smushkin, MD and Adrian Vella, MD \\ Division of Endocrinology \& Metabolism, Mayo Clinic, Rochester, MN
}

\begin{abstract}
Purpose of review-To provide an overview of the genetics of type 2 diabetes in the context of recent progress in the understanding of the genetic architecture of the disease and its applicability to the pathogenesis of the disease as well as efforts to individualize therapy in type 2 diabetes. Efforts are underway to understand how these loci alter measurable physiologic processes in nondiabetic humans. However, it is important to understand the potential pitfalls in such studies and the limitations underlying measurement of insulin secretion and action using qualitative methodologies.
\end{abstract}

Recent findings-The availability of large population-based cohorts and the ease with which large numbers of common genetic variants can be genotyped has enabled the discovery of multiple loci and pathways associated with type 2 diabetes. Recent efforts examining quantitative traits such as fasting glucose concentrations have led to the discovery of other genes likely to be important in the development of diabetes.

Summary-The past 4 years have witnessed a significant increase in our understanding of genetic predisposition to type 2 diabetes. Hopefully more progress will be made in applying this knowledge to the pathophysiology of type 2 diabetes in the coming years.

\section{Keywords}

Type 2 diabetes; genetic predisposition; quantitative traits

\section{Introduction}

Type 2 diabetes is a complex and pleomorphic metabolic disorder arising from a complex interaction between genes and the environment. It is characterized by defects in insulin secretion and insulin action which lead to hyperglycemia [1]. Indeed hyperglycemia is used to define the presence or absence of the disease: - fasting hyperglycemia (>126 mg/dl), after an oral glucose tolerance challenge $(120 \mathrm{~min}$ value $>200 \mathrm{mg} / \mathrm{dl}$ ) or if a random glucose $>200 \mathrm{mg} / \mathrm{dl}$, on two or more occasions. However, it has long been recognized that people with impaired fasting glucose and or impaired glucose tolerance have characteristics similar to people with established type 2 diabetes. Moreover, the more significant the elevation in fasting or post-challenge glucose concentrations, the more likely is the transition to type 2 diabetes $[2,3]$.

The concurrent availability of high-throughput genotyping techniques and large, multicenter case-control cohorts since 2006 has enabled the discovery of multiple common genetic variants associated with type 2 diabetes [4] or intermediate phenotypes such as glucoseinsulin ratios in response to a standardized challenge [5].

Address for Correspondence: Adrian Vella MD, Endocrine Research Unit, 5 Jo -194, Mayo Clinic, 200 First ST SW, Rochester, MN55905, (T), 507-255-6515, (F) 507-255-4828, vella.adrian@ mayo.edu.

Conflict of Interest: None 


\section{The genetic architecture of type 2 diabetes}

At the present time, knowledge of loci conferring risk of diabetes is limited to two extremes of a spectrum - extremely rare variants conferring disease risk in highly penetrant, autosomal dominant fashion or, conversely, common variants (minor allele frequency $\geq$ $10 \%$ ) with weak to modest effects on disease predisposition (Odds Ratio 1.1-1.5). In some cases, variation in a single locus can fit both extremes of the spectrum. For example, variation in WFS1 can cause the mendelian disorder of Wolfram Syndrome (Diabetes Insipidus, Diabetes Mellitus, Optic Atrophy and Deafness - DIDMOAD) while other (much more) common variants are associated with type 2 diabetes [6]. The discovery of less common, more penetrant variants likely awaits the application of whole genome sequencing to large kindreds with a high prevalence of the disease.

In this sense the genetic architecture of type 2 diabetes differs significantly from that of type 1 disease where risk is also conferred by multiple loci. However, in the latter case, some loci have far more significant effect on disease e.g. rs3129934 in HLA class II (OR 7) as well as, variants in INS and PTPN22 (OR > 2). Other variants in loci such as IL2RA and CTLA4 have effects on disease predisposition similar to those observed in type 2 diabetes [7]. The discovery of the association of IL2RA with type 1 diabetes served to illustrate some of the limitations of genetic association studies [8]. CD25, which is encoded by IL2RA is involved in immune regulation and is a phenotypic marker of $\mathrm{T}$ cells likely to regulate autoreactive clones; involvement in the pathogenesis of type 1 diabetes was not surprising. It also illustrated the sample size necessary to reliably detect association of relatively common variants with weak effect on disease predisposition [9]. Furthermore, the successful use of tag SNPs to detect a disease locus underpinned subsequent genome-wide association studies (GWAS) efforts. One final comment regards the statistical criteria necessary to accept an association as true - conventional correction for multiple testing is somewhat pointless - and depends on a priori knowledge of the prior odds against an association being true [10]. It is important to appreciate that some alternative measures to a pre-specified $P$-value for ranking signals in association studies may be susceptible to the minor allele frequency of the variants tested [11].

One significant advantage that genome-wide association studies (GWAS) have over candidate gene association studies is that they make no assumptions about disease pathogenesis. In contrast, candidate gene-based studies by definition assume that genes selected for study are important in disease pathogenesis, and therefore such studies are unlikely to discover novel mechanisms or pathways that lead to disease. This has indeed been the case with multiple loci associated with type 2 diabetes via GWAS which have unknown function or have been implicated in other disease states. Although the discovery of the association of TCF7L2 with type 2 diabetes preceded the advent of GWAS, the methodology (and rationale) used was similar and similarly directed. Indeed prior to the discovery that genetic variation in $T C F 7 L 2$ is associated with type 2 diabetes other than the suggestion that it may regulate the differential processing of proglucagon, little was known about its function [12]. This is not to say that subsequent to its discovery, the body of knowledge regarding the function of TCF7L2 has been consistent - a problem we will take up in the next section - however, it illustrates how undirected scientific inquiry can identify genes, pathways and processes not previously associated with a disease [13-16] (See Table 1 and 2).

Compared to a simple regression model incorporating blood pressure, triglycerides, HDL, glucose, body mass index and family history of diabetes, an identical model incorporating genetic information from 18 diabetes risk alleles had no predictive advantage for type 2 diabetes [17]. On an individual basis such data is of little use in predicting future risk of 
diabetes. However, by implicating a biological pathway in the pathogenesis of diabetes, genetic association studies have provided a greater understanding of the pathophysiology of type 2 diabetes and identified potential new drug targets for the treatment of the disease. It may be important to emphasize at this point that magnitude of effect a locus has on disease development does not preclude significant therapeutic effects of compounds acting on these loci. For example, sulfonylureas $(K C N J 11)$ and thiazolidinediones $(P P A R G)$ both have very significant effects on glycemic control although the common variants in these loci have weak associations with type 2 diabetes [4].

Initial GWAS studies used the presence of diabetes as a categorical trait (i.e. present or absent) and discovered several other loci associated with the disease (Table 1 and Table 2). In one case, FTO, the association with diabetes disappeared after correcting for BMI - the disease-associated variant predisposes to disease by increasing weight. Subsequently, analysis of quantitative traits such as fasting and 2-hour glucose concentrations has detected other loci that alter glucose homeostasis $[5,18,19]$. In the past year, MTNRIB which encodes the melatonin receptor 2 , expressed in $\beta$-cells and has been recently shown to alter fasting glucose. It also increases the risk of type 2 diabetes [20] (Table 2 and 3).

Reduced birth weight is associated with risk of type 2 diabetes in several large studies. The HBCS study has suggested that the disease-associated variant in HHEX-IDE was also associated with low-birth weight. Conversely the opposite was noted with $C D K N 2 A / 2 B$. However, risk variants in some loci interacted with low birth weight to further increase the risk of diabetes development [21]. Subsequently, a larger cohort of mothers and their offspring suggested that CDKAL1 and HHEX-IDE but not CDKN2A/2B, IGF2BP2 and $S L C 30 A 8$ also affected birthweight [22]. More recently, in a smaller cohort $(\sim 5,500)$ of children of European ancestry (and in whom gestational age at birth was unknown) only CDKALl was associated with birth-weight [23].

\section{Effect of disease-associated variants on measurable physiology}

One significant disadvantage of tag SNP methodology is that the subsequent elucidation of an etiological variant within the associated locus may not be straightforward. For example $I L 2 R A$ is adjacent to IL15RA - another plausible candidate gene for type 1 diabetes therefore a variant within the region may be associated with disease not because it is the true etiologic variant but because it is in linkage disequilibrium with it [8]. Similarly, the presence of a variant which causes a coding change in the gene product does not automatically qualify as the etiological variant. In such instances, fine-mapping of the locus is necessary to identify a variant (or variants) most associated with disease and with some measurable effect on physiology [24,25].

In type 2 diabetes some disease-associated variants have been associated with an intermediate phenotype such as insulin concentrations after a glucose challenge - a qualitative measure of insulin secretion - or with glucose/insulin ratios which have been used as a crude and imperfect measure of insulin action [26,27]. Indeed, subsequent to the discovery of the association of TCF7L2 with diabetes [28] analysis of OGTT data suggested that the (T) allele of rs7903146 impaired insulin secretion [27,29,30]. However, fine mapping of the locus in several populations was required to demonstrate that if rs7903146 is not the causative variant for type 2 diabetes, it is indistinguishable from it [31].

Unfortunately, such qualitative measures of insulin secretion and action cannot account for the compartmental kinetics, the pulsatile nature of insulin secretion or hepatic insulin clearance [32]. Attempts to better characterize the effect of TCF $7 L 2$ on insulin secretion and action using modelling has yielded contradictory results; for example, Elbein et al. reported an effect on insulin action alone [33]. 
Although it is reasonable to expect that a better measure of the phenotype (e.g.: insulin secretion) being tested will require smaller numbers than would be required with a cruder measure (e.g.: insulinogenic index). However, designing such studies de novo requires a considerable amount of resources due to the frequent sampling and multiple immunochemical assays necessary to accurately measure secretion and action. Moreover, the sample size necessary to adequately power such studies is not certain and dependent on the effect size of the locus being tested. Another significant limitation is that the genetic architecture of many of the loci associated with type 2 diabetes is not well known creating uncertainty in the optimal design of such experiments if the etiologic variant at a given locus is unknown.

Consequently, most of the available data correlating genotype data with a physiologic phenotype has arisen out of large cohorts where simple phenotyping with oral glucose tolerance tests was already available. Consequently it is important to remember the limitations of homeostasis model assessment and other qualitative measures of insulin secretion and action. Stancakova et al. studied 5,327 non-diabetic men and concluded that 8 SNPs affected insulin concentrations 30 minutes after oral glucose challenge. However, 3 SNPs, including the diabetes-associated variant of KCNJ11 (a gene which affect $\beta$-cell function), were nominally associated with the Matsuda index - a correlate of insulin sensitivity. In addition, 4 diabetes-associated variants were associated with indices of proinsulin conversion to insulin [34]. Although proinsulin concentrations in the peripheral circulation are considered to be a marker of $\beta$-cell health, they do not necessarily reflect secretion as its half-life is much longer than that of insulin or indeed c-peptide [35].

Type 2 diabetes is characterized by impaired insulin secretion and action (defined as the ability of insulin to suppress glucose production and stimulate glucose uptake). In addition glucose effectiveness (the ability of glucose per se to stimulate its own uptake and suppress its own release) is also impaired. In the postprandial situation defective suppression of glucagon secretion as well as accelerated gastric emptying may also contribute to the postprandial hyperglycemia observed in diabetes. Arguably, none of these other phenotypes are adequately addressed by a glucose tolerance test [36].

This may be one reason why to date most of the loci associated with type 2 diabetes seem to affect insulin secretion but not insulin action. Anther potential explanation is the modification of insulin action by environmental factors (that lead to weight gain) which outweigh any potential genetic effects. It is also important to remember that insulin secretion declines in concert with insulin action in impaired fasting glucose and impaired glucose tolerance [2]. Furthermore interventions, which decrease insulin secretion, lead to a measurable decrease in hepatic insulin action [37]. Finally, insulin secretion, when measured, is best expressed as a function of the prevailing insulin action [38].

More recently, over-expression of the $\alpha 2 \mathrm{~A}$-adrenergic receptor in mice was shown to decrease insulin secretion. Subsequently the same group of investigators demonstrated that in humans variation in $A D R A 2 A$ altered insulin response to intravenous glucose and was associated with type 2 diabetes [39]. Other novel loci have also been shown to alter fasting glucose as well as glucose and insulin responses to a standardized glucose challenge $[5,19]$.

\section{Variants associated with differential response to therapy}

From a physiologic point of view, monogenic disorders are helpful in illustrating the importance of specific gene products, and their associated pathways, to a given process e.g. glucose homeostasis. One such example is maturity onset diabetes of the young (MODY): mutations in the glucokinase gene (GCK - MODY 2) alter the set point at which insulin secretion occurs but insulin secretion and action are unimpaired in affected patients. 
Similarly, common variants in $G C K$ are also associated with alterations in fasting glucose concentrations. As progress is made in understanding the genetic architecture of diabetes, it may be possible to discern different pathophysiology within the heterogenous grouping of type 2 diabetes. In such situations, a given therapy may be more effective in one subgroup of patients than it is in another group of patients. At present there are some hints that this could be the case although the applicability to therapeutic selection in individual patients is uncertain. For example, in some subtypes of MODY, insulin secretagogues seem to be more effective than insulin sensitizers or insulin [40].

Unfortunately, as it applies to the therapy of common varieties of type 2 diabetes examples where common variation alters response to therapy are harder to come by. In part some of these limitations are due to the nature of the disease process; compliance with treatment and lifestyle are likely to affect response far more than common variation. Furthermore, deciding what endpoint to measure may be problematic when determining efficacy of a given therapy; while $\mathrm{HbA}_{1 \mathrm{c}}$ might be an obvious endpoint, the duration of study may not be long enough to allow meaningful changes in $\mathrm{HbA}_{1 \mathrm{c}}$ [41]. In a similar vein, a random glucose > $300 \mathrm{mg} / \mathrm{dL}$ is an arbitrary marker of sulfonylurea failure [42].

As discussed above, consideration needs to be taken of the genetic architecture of the locus under study. It is often wrong to assume that the presence of a variant identified by genomewide association to be associated with disease is the etiological variant or indeed the variant modulating drug response. A suggested approach would be one where a homogenous, wellcharacterized population is studied over a short (but physiologically meaningful) duration and a surrogate physiological variable (e.g.: insulin secretion) is utilized as a measure of response $[43,44]$.

Similar approaches have been undertaken to demonstrate that variation in TCF7L2 may alter response to infused GLP-1 [45] and that $O C T 1$ may alter response to oral metformin [46]. In the former study insulin secretion in response to hyperglycemia and GLP-1 was utilized as an endpoint while glucose excursion after an oral glucose tolerance test was used in the latter. However, a recent study examined the effect of 2 loss-of function polymorphisms in $O C T 1$ and concluded that the response to metformin was unaffected in 1,531 subjects with type 2 diabetes [47]. The same group of investigators has suggested that 2 variants causing loss-of-function of cytochrome p450 2C9 (which metabolizes sulfonylureas) improves the therapeutic response to sulfonylureas [48]. The Diabetes Prevention Program (DPP) has also shown that some disease-associated variants are associated with impaired response to metformin [49], however, such variants are likely of little value in predicted individual response to pharmacotherapy.

\section{Conclusion}

Common genetic variation is associated with type 2 diabetes and the discovery of loci that affect diabetes risk, response to oral glucose, incretin effect and fasting glucose concentrations will help understand the pathogenesis of the disease and identify new targets for drug development. However, it is important to understand the potential limitations of such knowledge and the difficulties in designing experiments to understand their role in glucose metabolism and their effect on drug response in humans.

\section{Acknowledgments}

Grant Support: Dr. Vella is supported by DK078646 


\section{References}

1. Ferrannini E. Insulin resistance versus insulin deficiency in non-insulin-dependent diabetes mellitus: problems and prospects. Endocr Rev. 1998 Aug; 19(4):477-90. [PubMed: 9715376]

2. Bock G, Dalla Man C, Campioni M, Chittilapilly E, Basu R, Toffolo G, et al. Pathogenesis of prediabetes: mechanisms of fasting and postprandial hyperglycemia in people with impaired fasting glucose and/or impaired glucose tolerance. Diabetes. 2006 Dec; 55(12):3536-49. [PubMed: 17130502]

3. Dinneen SF, Maldonado D 3rd, Leibson CL, Klee GG, Li H, Melton LJ 3rd, et al. Effects of changing diagnostic criteria on the risk of developing diabetes. Diabetes Care. 1998 Sep; 21(9): 1408-13. [PubMed: 9727885]

4••. Stolerman ES, Florez JC. Genomics of type 2 diabetes mellitus: implications for the clinician. Nature reviews. 2009 Aug; 5(8):429-36. A comprehensive review of common genetic variation and association with type 2 diabetes.

5••. Dupuis J, Langenberg C, Prokopenko I, Saxena R, Soranzo N, Jackson AU, et al. New genetic loci implicated in fasting glucose homeostasis and their impact on type 2 diabetes risk. Nat Genet. $2010 \mathrm{Feb}$; 42(2):105-16. This study identified 9 novel loci (out of a total of 16) which alter fasting glucose concentration. Five of these loci also confer risk of type 2 diabetes. [PubMed: 20081858]

6. Sandhu MS, Weedon MN, Fawcett KA, Wasson J, Debenham SL, Daly A, et al. Common variants in WFS1 confer risk of type 2 diabetes. Nat Genet. 2007 Aug; 39(8):951-3. [PubMed: 17603484]

7. Todd JA, Walker NM, Cooper JD, Smyth DJ, Downes K, Plagnol V, et al. Robust associations of four new chromosome regions from genome-wide analyses of type 1 diabetes. Nat Genet. 2007 Jul; 39(7):857-64. [PubMed: 17554260]

8. Vella A, Cooper JD, Lowe CE, Walker N, Nutland S, Widmer B, et al. Localization of a Type 1 Diabetes Locus in the IL2RA/CD25 Region by Use of Tag Single-Nucleotide Polymorphisms. Am J Hum Genet. 2005 May; 76(5):773-9. [PubMed: 15776395]

9. Wang WY, Barratt BJ, Clayton DG, Todd JA. Genome-wide association studies: theoretical and practical concerns. Nat Rev Genet. 2005 Feb; 6(2):109-18. [PubMed: 15716907]

10. Thomas DC, Clayton DG. Betting odds and genetic associations. J Natl Cancer Inst. 2004 Mar 17; 96(6):421-3. [PubMed: 15026459]

11•. Stromberg U, Bjork J, Vineis P, Broberg K, Zeggini E. Ranking of genome-wide association scan signals by different measures. International journal of epidemiology. 2009 Oct; 38(5):1364-73. An examination of five strategies for ranking putative associations in genome-wide association scans and the effect of minor allele frequency on these measures. [PubMed: 19734549]

12. Yi F, Brubaker PL, Jin T. TCF-4 mediates cell type-specific regulation of proglucagon gene expression by beta-catenin and glycogen synthase kinase-3beta. J Biol Chem. 2005 Jan 14; 280(2): 1457-64. [PubMed: 15525634]

13. Saxena R, Voight BF, Lyssenko V, Burtt NP, de Bakker PI, Chen H, et al. Genome-wide association analysis identifies loci for type 2 diabetes and triglyceride levels. Science. 2007 Jun 1; 316(5829):1331-6. [PubMed: 17463246]

14. Sladek R, Rocheleau G, Rung J, Dina C, Shen L, Serre D, et al. A genome-wide association study identifies novel risk loci for type 2 diabetes. Nature. 2007 Feb 22; 445(7130):881-5. [PubMed: 17293876]

15. Zeggini E, Scott LJ, Saxena R, Voight BF, Marchini JL, Hu T, et al. Meta-analysis of genomewide association data and large-scale replication identifies additional susceptibility loci for type 2 diabetes. Nat Genet. 2008 May; 40(5):638-45. [PubMed: 18372903]

16. Zeggini E, Weedon MN, Lindgren CM, Frayling TM, Elliott KS, Lango H, et al. Replication of genome-wide association signals in UK samples reveals risk loci for type 2 diabetes. Science. 2007 Jun 1; 316(5829):1336-41. [PubMed: 17463249]

17. Meigs JB, Shrader P, Sullivan LM, McAteer JB, Fox CS, Dupuis J, et al. Genotype score in addition to common risk factors for prediction of type 2 diabetes. N Engl J Med. 2008 Nov 20; 359(21):2208-19. [PubMed: 19020323] 
18. Bouatia-Naji N, Rocheleau G, Van Lommel L, Lemaire K, Schuit F, Cavalcanti-Proenca C, et al. A polymorphism within the G6PC2 gene is associated with fasting plasma glucose levels. Science. 2008 May 23; 320(5879):1085-8. [PubMed: 18451265]

19••. Saxena R, Hivert MF, Langenberg C, Tanaka T, Pankow JS, Vollenweider P, et al. Genetic variation in GIPR influences the glucose and insulin responses to an oral glucose challenge. Nat Genet. $2010 \mathrm{Feb} ; 42(2): 142-8$. Variation in GIPR - the receptor for the incretin hormone GIP altered insulin and glucose responses to an oral glucose challenge but was not associated with type 2 diabetes or fasting glucose. [PubMed: 20081857]

20••. Bouatia-Naji N, Bonnefond A, Cavalcanti-Proenca C, Sparso T, Holmkvist J, Marchand M, et al. A variant near MTNR1B is associated with increased fasting plasma glucose levels and type 2 diabetes risk. Nat Genet. 2009 Jan; 41(1):89-94. One of 3 concurrently-published studies establishing the association of MTNRIB with fasting glucose and type 2 diabetes. [PubMed: 19060909]

21 • Pulizzi N, Lyssenko V, Jonsson A, Osmond C, Laakso M, Kajantie E, et al. Interaction between prenatal growth and high-risk genotypes in the development of type 2 diabetes. Diabetologia (52). 2009 May.(5):825-9. An examination of the interaction of birth weight and type 2 diabetes genotypes on development of type 2 diabetes. [PubMed: 19225753]

22•. Freathy RM, Bennett AJ, Ring SM, Shields B, Groves CJ, Timpson NJ, et al. Type 2 diabetes risk alleles are associated with reduced size at birth. Diabetes. 2009 Jun; 58(6):1428-33. An examination of the effect of diabetes risk alleles on birth weight. [PubMed: 19228808]

23•. Zhao J, Li M, Bradfield JP, Wang K, Zhang H, Sleiman P, et al. Examination of type 2 diabetes loci implicates CDKAL1 as a birth weight gene. Diabetes. 2009 Oct; 58(10):2414-8. Diabetesassociated variation in CDKAL1 alters birth weight. [PubMed: 19592620]

24. Lowe CE, Cooper JD, Brusko T, Walker NM, Smyth DJ, Bailey R, et al. Large-scale genetic fine mapping and genotype-phenotype associations implicate polymorphism in the IL2RA region in type 1 diabetes. Nat Genet. 2007 Sep; 39(9):1074-82. [PubMed: 17676041]

25. Ueda H, Howson JM, Esposito L, Heward J, Snook H, Chamberlain G, et al. Association of the Tcell regulatory gene CTLA4 with susceptibility to autoimmune disease. Nature. 2003 May 29; 423(6939):506-11. [PubMed: 12724780]

26. Nielsen EM, Hansen L, Carstensen B, Echwald SM, Drivsholm T, Glumer C, et al. The E23K variant of Kir6.2 associates with impaired post-OGTT serum insulin response and increased risk of type 2 diabetes. Diabetes. 2003 Feb; 52(2):573-7. [PubMed: 12540638]

27. Florez JC, Jablonski KA, Bayley N, Pollin TI, de Bakker PI, Shuldiner AR, et al. TCF7L2 polymorphisms and progression to diabetes in the Diabetes Prevention Program. N Engl J Med. 2006 Jul 20; 355(3):241-50. [PubMed: 16855264]

28. Grant SF, Thorleifsson G, Reynisdottir I, Benediktsson R, Manolescu A, Sainz J, et al. Variant of transcription factor 7-like 2 (TCF7L2) gene confers risk of type 2 diabetes. Nat Genet. 2006 Jan 15 .

29. Damcott CM, Pollin TI, Reinhart LJ, Ott SH, Shen H, Silver KD, et al. Polymorphisms in the Transcription Factor 7-Like 2 (TCF7L2) Gene Are Associated With Type 2 Diabetes in the Amish: Replication and Evidence for a Role in Both Insulin Secretion and Insulin Resistance. Diabetes. 2006 Sep; 55(9):2654-9. [PubMed: 16936218]

30. Saxena R, Gianniny L, Burtt NP, Lyssenko V, Giuducci C, Sjogren M, et al. Common single nucleotide polymorphisms in TCF7L2 are reproducibly associated with type 2 diabetes and reduce the insulin response to glucose in nondiabetic individuals. Diabetes. 2006 Oct; 55(10):2890-5. [PubMed: 17003358]

31. Helgason A, Palsson S, Thorleifsson G, Grant SF, Emilsson V, Gunnarsdottir S, et al. Refining the impact of TCF7L2 gene variants on type 2 diabetes and adaptive evolution. Nat Genet. 2007 Feb; 39(2):218-25. [PubMed: 17206141]

32. Caumo A, Luzi L. First-phase insulin secretion: does it exist in real life? Considerations on shape and function. Am J Physiol Endocrinol Metab. 2004 Sep; 287(3):E371-85. [PubMed: 15308473]

33. Elbein SC, Chu WS, Das SK, Yao-Borengasser A, Hasstedt SJ, Wang H, et al. Transcription factor 7-like 2 polymorphisms and type 2 diabetes, glucose homeostasis traits and gene expression in US participants of European and African descent. Diabetologia. 2007 Aug; 50(8):1621-30. [PubMed: 17579832] 
34••. Stancakova A, Kuulasmaa T, Paananen J, Jackson AU, Bonnycastle LL, Collins FS, et al. Association of 18 confirmed susceptibility loci for type 2 diabetes with indices of insulin release, proinsulin conversion, and insulin sensitivity in 5,327 nondiabetic Finnish men. Diabetes. 2009 Sep; 58(9):2129-36. Qualitative measures of insulin secretion and action as well as proinsulin conversion to insulin were correlated with diabetes risk alleles. [PubMed: 19502414]

35. Kendall DM, Riddle MC, Rosenstock J, Zhuang D, Kim DD, Fineman MS, et al. Effects of exenatide (exendin-4) on glycemic control over 30 weeks in patients with type 2 diabetes treated with metformin and a sulfonylurea. Diabetes Care. 2005 May; 28(5):1083-91. [PubMed: 15855571]

36••. Staiger H, Machicao F, Fritsche A, Haring HU. Pathomechanisms of type 2 diabetes genes. Endocr Rev. 2009 Oct; 30(6):557-85. An examination of published studies examining the mechanisms by which diabetes risk alleles lead to type 2 diabetes. [PubMed: 19749172]

37. Matveyenko AV, Veldhuis JD, Butler PC. Mechanisms of impaired fasting glucose and glucose intolerance induced by an approximate 50\% pancreatectomy. Diabetes. 2006 Aug; 55(8):2347-56. [PubMed: 16873700]

38. Breda E, Cavaghan MK, Toffolo G, Polonsky KS, Cobelli C. Oral glucose tolerance test minimal model indexes of beta-cell function and insulin sensitivity. Diabetes. 2001 Jan; 50(1):150-8. [PubMed: 11147781]

39••. Rosengren AH, Jokubka R, Tojjar D, Granhall C, Hansson O, Li DQ, et al. Overexpression of alpha2A-adrenergic receptors contributes to type 2 diabetes. Science. 2010 Jan 8; 327(5962): 217-20. A congenic region in mice and humans encompassing the $\alpha 2 \mathrm{~A}$ adrenergic receptor alters insulin secretion when overexpressed in mice. Subsequently, variants in this locus were shown to alter insulin response during an intravenous glucose tolerance test in humans. These variants were associated with type 2 diabetes in an independent cohort. [PubMed: 19965390]

40. Hattersley AT, Pearson ER. Minireview: pharmacogenetics and beyond: the interaction of therapeutic response, beta-cell physiology, and genetics in diabetes. Endocrinology. 2006 Jun; 147(6):2657-63. [PubMed: 16556760]

41 • Becker ML, Visser LE, van Schaik RH, Hofman A, Uitterlinden AG, Stricker BH. Genetic variation in the organic cation transporter 1 is associated with metformin response in patients with diabetes mellitus. Pharmacogenomics J. 2009 Apr 21. A short-term study which used $\mathrm{HbA}_{1 \mathrm{c}}$ as an endpoint and suggested that a SNP in SLC22A1 altered response to metformin.

42. Sesti G, Laratta E, Cardellini M, Andreozzi F, Del Guerra S, Irace C, et al. The E23K variant of KCNJ11 encoding the pancreatic beta-cell adenosine 5'-triphosphate-sensitive potassium channel subunit Kir6.2 is associated with an increased risk of secondary failure to sulfonylurea in patients with type 2 diabetes. J Clin Endocrinol Metab. 2006 Jun; 91(6):2334-9. [PubMed: 16595597]

43. Grudell AB, Sweetser S, Camilleri M, Eckert DJ, Vazquez-Roque MI, Carlson PJ, et al. A controlled pharmacogenetic trial of sibutramine on weight loss and body composition in obese or overweight adults. Gastroenterology. 2008 Oct; 135(4):1142-54. [PubMed: 18725220]

44. Vella A, Camilleri M. Pharmacogenetics: potential role in the treatment of diabetes and obesity. Expert opinion on pharmacotherapy. 2008 May; 9(7):1109-19. [PubMed: 18422469]

45. Schafer SA, Tschritter O, Machicao F, Thamer C, Stefan N, Gallwitz B, et al. Impaired glucagonlike peptide-1-induced insulin secretion in carriers of transcription factor 7-like 2 (TCF7L2) gene polymorphisms. Diabetologia. 2007 Dec; 50(12):2443-50. [PubMed: 17661009]

46. Shu Y, Sheardown SA, Brown C, Owen RP, Zhang S, Castro RA, et al. Effect of genetic variation in the organic cation transporter 1 (OCT1) on metformin action. J Clin Invest. 2007 May; 117(5): 1422-31. [PubMed: 17476361]

47• Zhou K, Donnelly LA, Kimber CH, Donnan PT, Doney AS, Leese G, et al. Reduced-function SLC22A1 polymorphisms encoding organic cation transporter 1 and glycemic response to metformin: a GoDARTS study. Diabetes. 2009 Jun; 58(6):1434-9. The investigators studied 3,450 patients with type 2 diabetes who were incident users of metformin and examined the effects of two polymorphisms in SLC22A1 on metformin response. This gene encodes organic cation transporter 1 which mediates hepatic uptake of metformin and is necessary for its glycemic effects. No effect on $\mathrm{HbA}_{1 \mathrm{c}}$ reduction was reported. [PubMed: 19336679]

48 . Zhou K, Donnelly L, Burch L, Tavendale R, Doney AS, Leese G, et al. Loss-of-function CYP2C9 variants improve therapeutic response to sulfonylureas in type 2 diabetes: a Go-DARTS study. 
Clin Pharmacol Ther. 2010 Jan; 87(1):52-6. In 1,073 users of sulfonylureas, 2 CYP2C9 variants which impair substrate clearance were associated with a $0.5 \%$ greater reduction in $\mathrm{HbA}_{1 \mathrm{c}}$ over at least 6-months of treatment. [PubMed: 19794412]

49. Florez JC, Jablonski KA, Kahn SE, Franks PW, Dabelea D, Hamman RF, et al. Type 2 diabetesassociated missense polymorphisms KCNJ11 E23K and ABCC8 A1369S influence progression to diabetes and response to interventions in the Diabetes Prevention Program. Diabetes. 2007 Feb; 56(2):531-6. [PubMed: 17259403] 


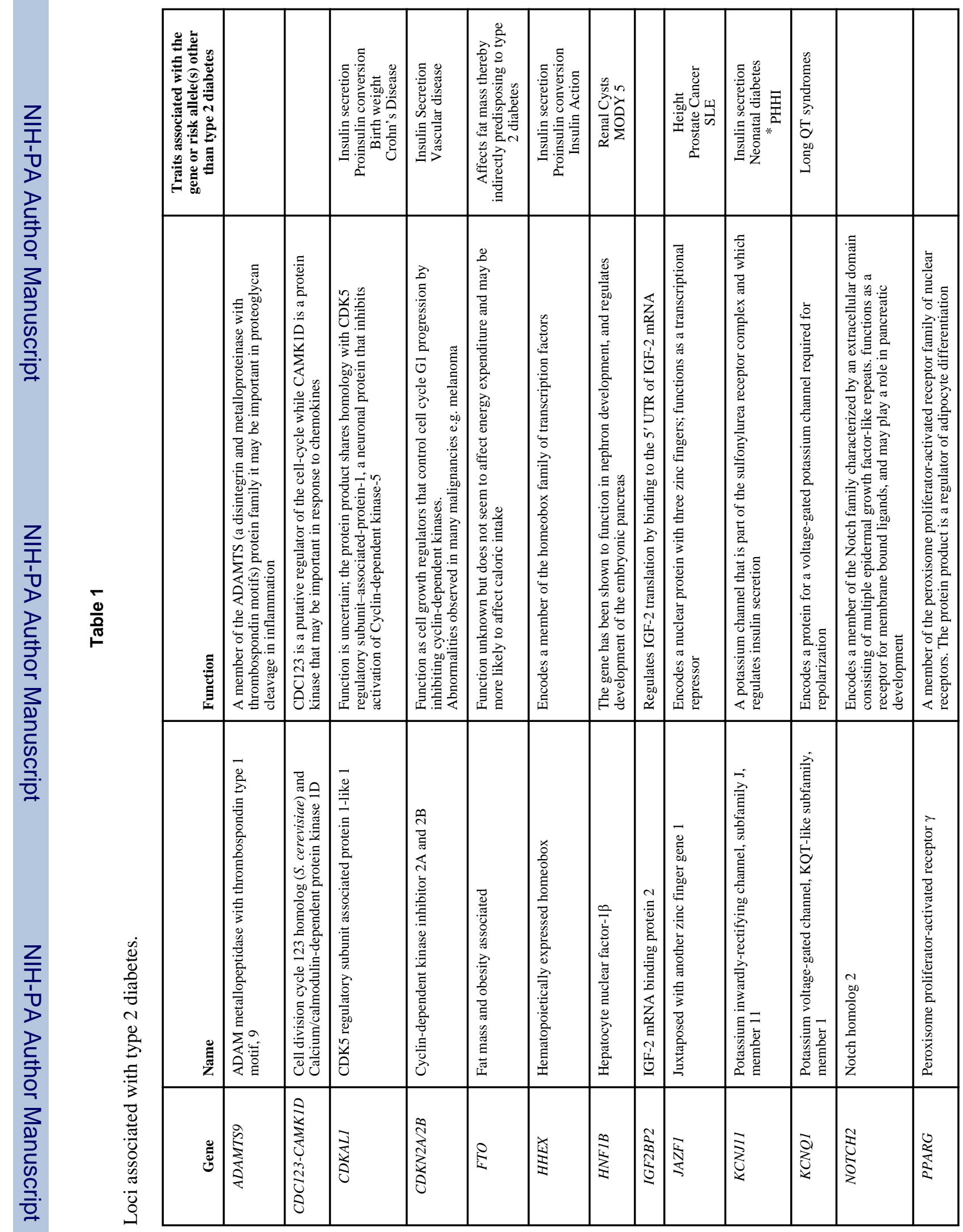

Curr Opin Clin Nutr Metab Care. Author manuscript; available in PMC 2011 July 1. 


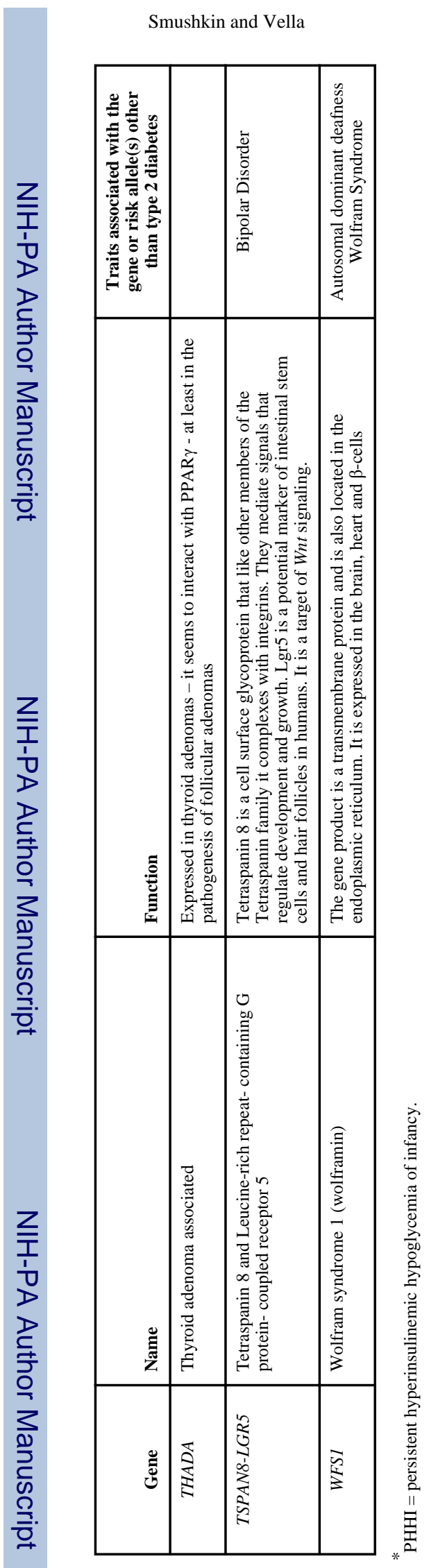

Curr Opin Clin Nutr Metab Care. Author manuscript; available in PMC 2011 July 1. 


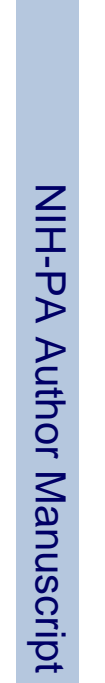

\begin{tabular}{|c|c|c|c|c|c|c|c|c|c|c|}
\hline & 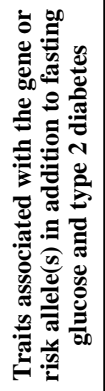 & & 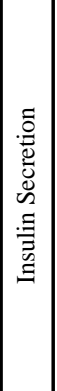 & & & & 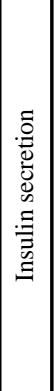 & & 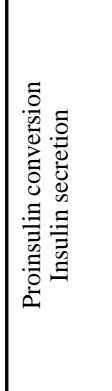 & 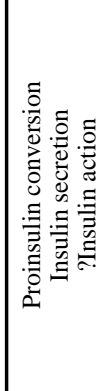 \\
\hline & 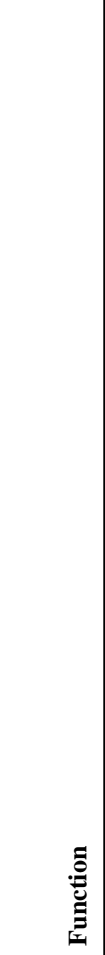 & 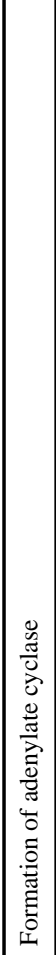 & 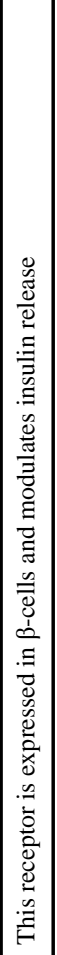 & 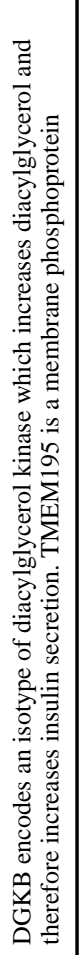 & 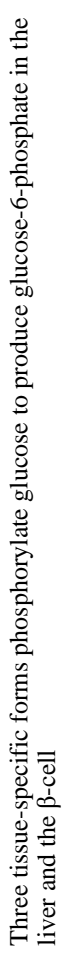 & 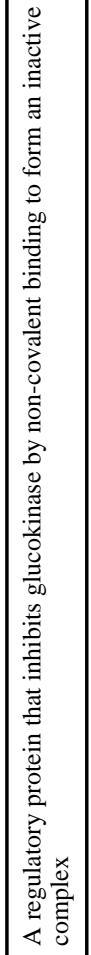 & 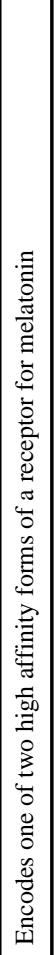 & 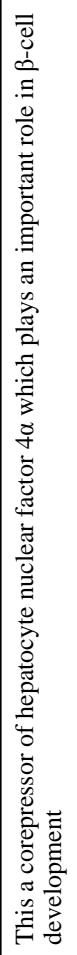 & 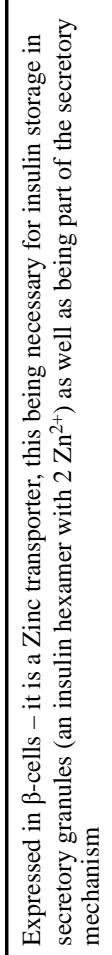 & 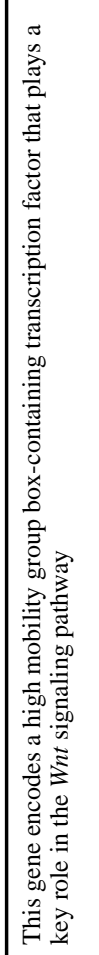 \\
\hline 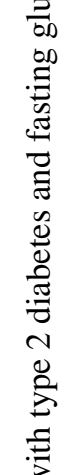 & $\begin{array}{l}\text { Еूँ } \\
\text { Zू }\end{array}$ & 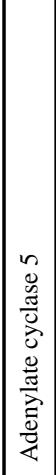 & 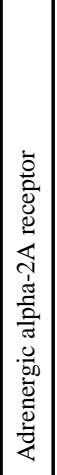 & 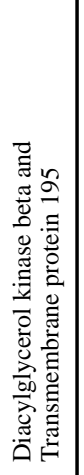 & 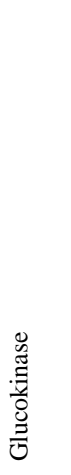 & 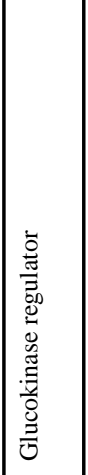 & 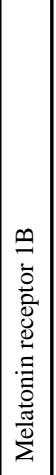 & 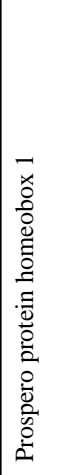 & 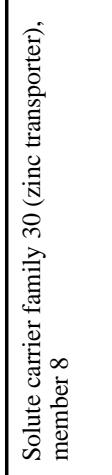 & 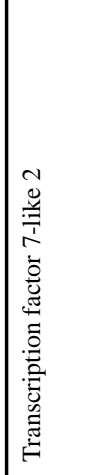 \\
\hline 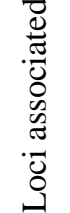 & שّ: & 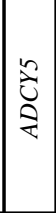 & 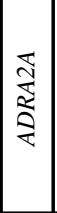 & 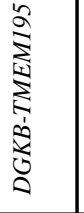 & త্ট & 通 & 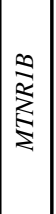 & 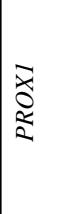 & 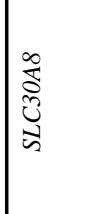 & \begin{tabular}{l}
$\tilde{N}$ \\
\multirow{N}{E}{} \\
D
\end{tabular} \\
\hline
\end{tabular}

Curr Opin Clin Nutr Metab Care. Author manuscript; available in PMC 2011 July 1. 


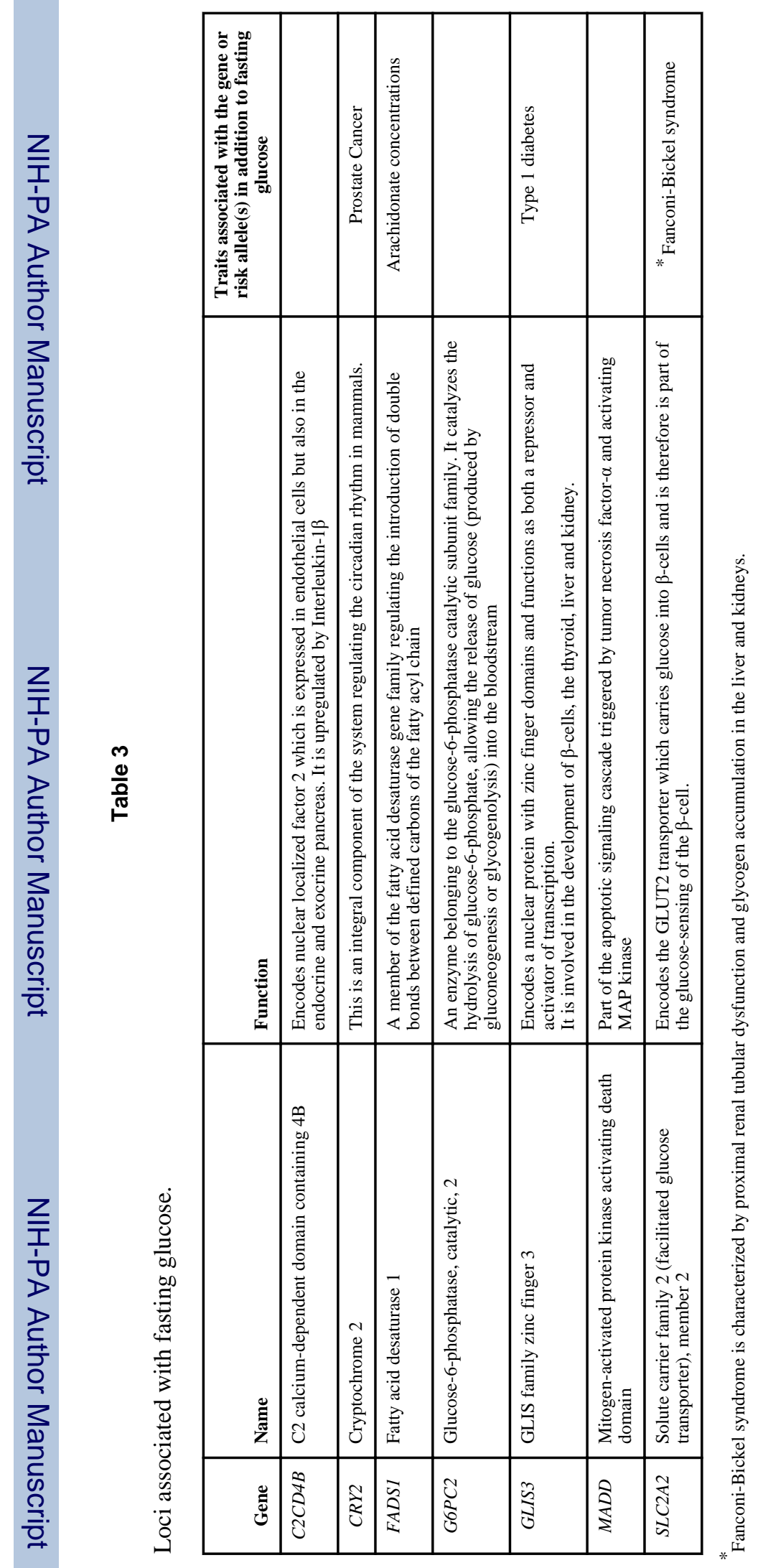

Curr Opin Clin Nutr Metab Care. Author manuscript; available in PMC 2011 July 1. 